\title{
Use of coculture of colonic mucosal biopsies to investigate the release of eicosanoids by inflamed and uninflamed mucosa from patients with inflammatory bowel disease
}

\author{
T D Wardle, L Hall, L A Turnberg
}

\begin{abstract}
Eicosanoid production was measured in cultured biopsies of colonic mucosa from control patients, with the irritable bowel syndrome, and from patients with proctosigmoiditis and with colonic Crohn's disease. Cultured inflamed colonic mucosa from patients with proctosigmoiditis and Crohn's disease produced more prostaglandin $\mathrm{E}_{2}$ and leukotrienes $\mathbf{C}_{4}$ than control tissues. In addition, eicosanoid production by macroscopically uninflamed or 'quiescent' mucosa from the right colon was examined in patients with proctosigmoiditis and between skip lesions in Crohn's disease patients. In the proctosigmoiditis group quiescent mucosa produced eicosanoids in similar quantities to control tissue. Coculture of quiescent plus inflamed tissue however, generated a marked increase in eicosanoid output in 12 of 20 of the patients and this was similar to the quantity obtained from two pieces of inflamed tissue. In the Crohn's disease group, quiescent mucosa produced more eicosanoids than control mucosa but production was markedly stimulated by coculture with inflamed mucosa in all patients. These findings suggest that in some patients with proctosigmoiditis and in all patients with Crohn's disease quiescent mucosa appears to be sensitised. A small but significant increase in the macrophage population may be partly responsible but it is likely that these and other cells are primed to release eicosanoids, and may be induced to do so by soluble mediators produced by actively inflamed tissue.
\end{abstract}

(Gut 1992; 33: 1644-1651)

Production of prostaglandins and leukotrienes is increased in the mucosa of patients with inflammatory bowel disease. ${ }^{12}$ Several of these arachidonic acid derivatives are capable of stimulating intestinal secretion, of influencing smooth muscle contractility, and of amplifying and propagating the inflammatory reaction, ${ }^{1-8}$ and thus are likely to be involved in the pathophysiology of the disease. They are released from mesenchymal inflammatory cells and there are several potential stimuli for their release. It is likely that the increase in eicosanoid production is the result of a combination of an increase in the number of relevant inflammatory cells, an increase in the drive to production by a greater stimulus than normal, and an increased production rate by specifically primed cells, but the relative contribution of these is uncertain. We took advantage of the fact that patients with proctosigmoiditis and some patients with Crohn's colitis have macroscopically normal areas of mucosa coexisting with their abnormal, inflamed mucosa. We reasoned that it may be possible to detect evidence of a population of cells in 'quiescent' mucosa, which were primed to produce excessive amounts of eicosanoids when stimulated, and we utilised the technique of coculture of biopsy specimens from such patients for these studies.

\section{Methods}

\section{PATIENTS}

Forty patients underwent colonoscopy after a bowel preparation consisting of a three day low residue diet followed by a combination of ' $\mathrm{X}$ prep' (purified senna extract, $1 \mathrm{ml} / \mathrm{kg}$ body weight) and $10 \%$ mannitol $(500 \mathrm{ml}$, one day before the examination). In patients with inflammatory bowel disease, however, both the concentration and quantity of both compounds were reduced according to the severity of the patient's symptoms

The control group comprised 10 patients (three men, seven women, mean age 34 years) with irritable bowel syndrome. Mucosal biopsy specimens, taken from the caecum, ascending, transverse, descendings and sigmoid colon, and the rectum, were endoscopically and histologically normal, in these 10 subjects.

The study group consisted of: (a) Twenty patients (12 men, eight women, mean age 36.8 years) with active distal proctosigmoiditis. Each patient had colonic biopsies taken from endoscopically inflamed distal mucosa, as well as proximal, macroscopically normal, ('quiescent') mucosa from the transverse or ascending colon. Ten patients were taking mesalazine $(400 \mathrm{mg}$ tds) three sulphasalazine ( $1 \mathrm{~g} \mathrm{tds}$ ) and seven were using topical steroids (od) at the time of colonoscopy. (b) Ten patients (four men, six women, mean age 39.4 years) with active Crohn's colitis who had biopsy specimens taken from macroscopically inflamed and uninflamed mucosa ('quiescent'). Six patients were taking prednisolone (ranging from 5-15 mg daily), two patients were taking mesalazine ( $400 \mathrm{mg}$ tds) and two were taking a combination of these.

The severity of inflammation was graded, on a four point scale corresponding to: (1) Macroscopically normal. (2) Granular mucosa, contact bleeding. (3) Erythematous mucosa, oedematous 

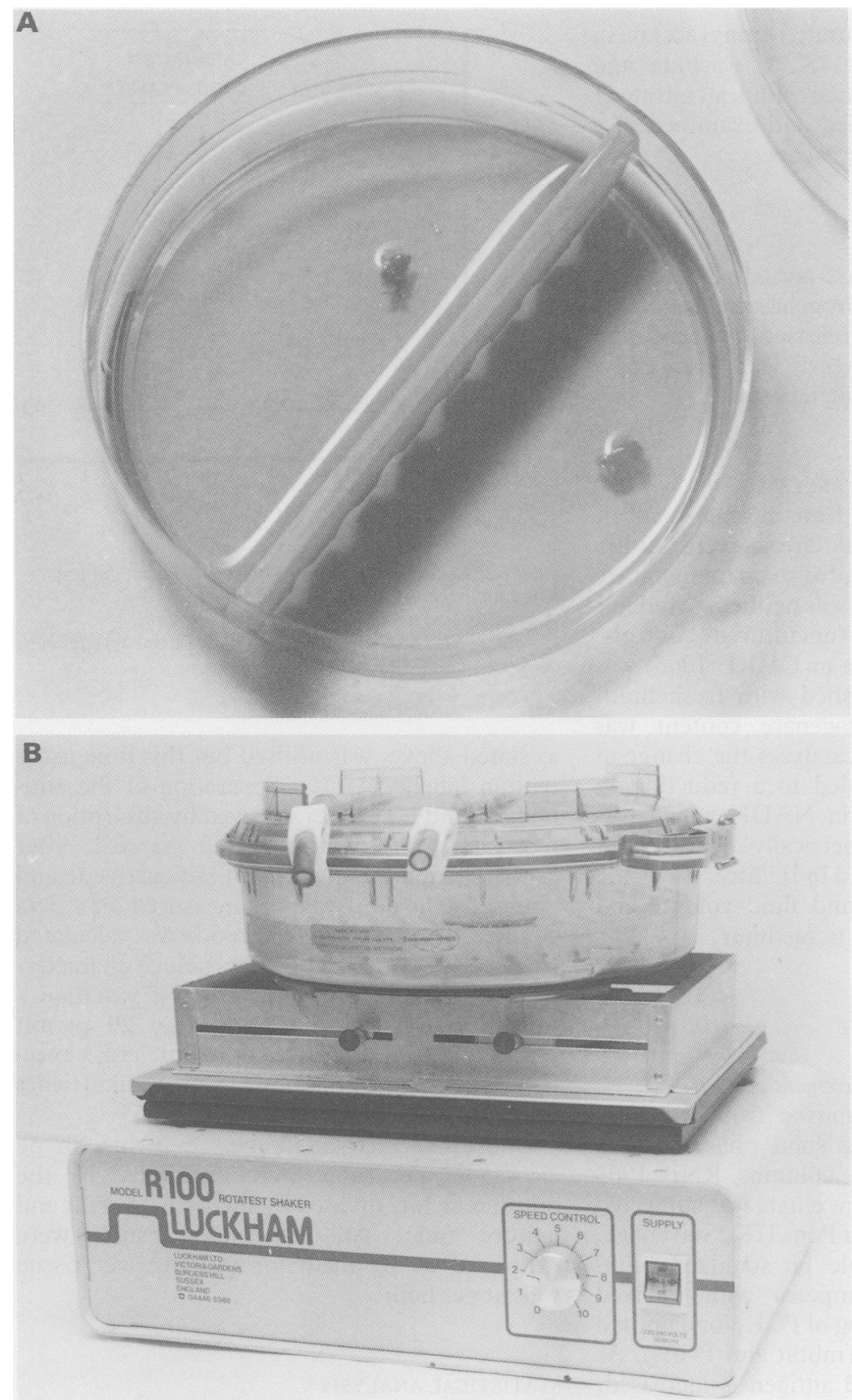

Figure 1: Coculture plate (A) inside humidified chamber mounted on a rotary shaker (B).

superficial ulceration. (4) Deep ulceration with slough, pseudopolyp formation.

Biopsies were taken from both inflamed tissue - graded 3/4, and quiescent tissue - graded 1 . All biopsies were taken with non-spiked forceps to minimise tissue trauma. These studies were approved by the Salford Health Authority Ethics Committee.

\section{TISSUE CULTURE}

Immediately after taking the biopsy specimens, they were placed in L15 (a commercial transport medium) with added penicillin $G$ and streptomycin sulphate and transferred to the laboratory. The tissue was gently washed three times, in L15 medium, blotted carefully, weighed (range 2-7 $\mathrm{mg}$ ) and placed in $1 \mathrm{ml}$ of a culture medium (CMRL 1066 plus glucose $5 \mu \mathrm{g} / \mathrm{ml}$; methionine
$1 \mu \mathrm{M} / \mathrm{ml}$, tris buffer $20 \mathrm{mM}$; glutamine $3 \mu \mathrm{M} /$ $\mathrm{ml}$; $\beta$-retinyl acetate $1 \mu \mathrm{g} / \mathrm{ml}$; penicillin $\mathrm{G} 100$ $\mathrm{IU} / \mathrm{ml}$; streptomycin sulphate $100 \mu \mathrm{g} / \mathrm{ml}$; gentamicin $50 \mu \mathrm{g} / \mathrm{ml}$; amphoteracin $\beta$ $0.25 \mu \mathrm{g} / \mathrm{ml}$ ) in a modified $5 \mathrm{~cm}$ petri dish (Fig l). The dish was divided by a polypropylene barrier that was designed to allow free circulation of the $1 \mathrm{ml}$ culture medium, but to prevent direct contact between two pieces of tissue. Multiple biopsies were taken from each patient; thus various combinations of pairs of the three tissue types, control, inflamed and 'quiescent', were cultured. The coculture plates were placed in a humidified chamber maintained at $37^{\circ} \mathrm{C}$, supplied with a mixture of $95 \%$ oxygen $/ 5 \%$ carbon dioxide and gently rotated at 10 cycles/ minute (Fig 1). After four hours of coculture the medium was removed, divided into two aliquots and the concentrations of $\mathrm{PGE}_{2}$ and $\mathrm{LTC}_{4}$ were measured.

\section{HISTOLOGY}

(a) Biopsy specimens from each patient were fixed in $10 \%$ buffered formalin and embedded in paraffin wax after dehydration, clearing, and impregnation. Subsequent $4 \mu \mathrm{m}$ sections were stained with haematoxylin and eosin. The inflammatory cell infiltrate was graded, on a four point scale corresponding to none, mild, moderate or severe, the observer being unaware of the source of the biopsy. ${ }^{9}$ Correlations were sought between the histological grade, endoscopic appearance and eicosanoid levels.

(b) Parallel biopsies, from caecum, ascending, transverse, descending, and sigmoid colon and the rectum were fixed in $2.5 \%$ glutaraldehyde for three hours. The biopsies were then washed in sodium cacodylate $(0 \cdot 1 \mathrm{~m}, \mathrm{pH} 7 \cdot 4)$ followed by four, two hour sequential changes of the same, before placing in $2 \%$ osmium tetroxide for one hour. After dehydration and treatment with acetone, the tissues were placed in a 50:50 resin (Araldite CYH212) acetone mix for two to six hours, before impregnation with resin (12 hours) and then polymerisation at $60^{\circ} \mathrm{C}(42$ hours) and processed as detailed below. One micron sections were stained with $1 \%$ toluidine blue in $1 \%$ disodium tetraborate, differentiated in $100 \%$ alcohol and mounted in DPX. The sections were examined through a Nikon microscope under oil immersion ( $\times 10$ ocular; $\times 100$ objective). After calibration of an eye piece graticule, the section was positioned over a $2000 \mu \mathrm{m}^{2}$ counting area ensuring that the crypts were perpendicular to the muscularis mucosae and the corner of the counting grid was adjacent to the bottom of the crypt. The number of neutrophils, eosinophils, mast cells, macrophages, lymphocytes, and plasma cells were counted within this area. Ten different areas were examined. All sections were coded so that the microscopist could not know any patient details or the anatomical site from which the biopsies were taken.

(c) All three types of tissue were sampled, before and after culture, fixed in glutaraldehyde, processed, impregnated and polymerised as previously described. The resin blocks were sectioned (60-70 nm), using glass knives in a Reichardt ultramicrotome, mounted on copper 
grids and immersed in saturated uranyl acetate in $50 \%$ ethanol (one hour). After washing and drying the grids were treated with lead citrate (1 minute), washed and dried and examined in a transmission electron microscope.

\section{TISSUE VIABILITY}

In view of the brief culture period viability was assessed by lactate dehydrogenase release. This intracellular enzyme is released by dead and dying cells. Structural integrity was assessed by electron microscopy, as detailed above.

\section{LACTATE DEHYDROGENASE RELEASE}

Paired mucosal biopsies from normal control, quiescent, and inflamed areas were either cultured or allowed to stand at room temperature in $1 \mathrm{ml} 0.9 \%$ saline which was neither stirred nor gassed, to act as parallel (uncultured) controls. The $1 \mathrm{ml}$ medium (saline or CMRL 1066) was removed hourly, replenished with fresh fluid, and the lactate dehydrogenase content was measured. This enzyme catalyses the change of lactate to pyruvate coupled to a reduction in $\mathrm{NAD}$, and the increase in NADH which was measured spectrophotometrically at $340 \mathrm{~nm}$. The results were calculated in IU/litre, corrected for tissue weight, time and fluid volume and expressed as IU/ $\mu \mathrm{g}$ of wet tissue/hour.

\section{EICOSANOID MEASUREMENT}

\section{(a) Prostaglandin $E_{2}$ measurement}

Prostaglandin $E_{2}$ was removed from the $1 \mathrm{ml}$ aliquot of medium using solid phase sorbent extraction utilising mini columns RNP 1903 (Amersham). The resultant eluate was subjected to radioimmunoassay (Du Pont UK, Stevenage, Herts, UK). The sample or standard (nonradioactive antigen) competes with a fixed amount of iodinated analog of $\mathrm{PGE}_{2}$ for a limited number of binding sites (rabbit anti $\mathrm{PGE}_{2}$ ). As the amount of unlabelled antigen is increased, the number of antibody binding sites is reduced. The antibody-antigen complexes were then separated from the free antigen by precipitation (polyethylene glycol) and subsequent centrifugation. The supernatant was decanted and the antibody-antigen complex was counted in a gamma counter. Results from the standards were used to construct a curve from which the unknowns were read by interpolation. Performance characteristics of this technique were assessed by adding known quantities of $\mathrm{PGE}_{2}$ to culture medium. Intra and inter assay variation were $11 \mathrm{pg} / \mathrm{ml}$ and $60 \mathrm{pg} / \mathrm{ml}$ respectively; recovery $96 \%$; sensitivity $0.8 \mathrm{pg} / \mathrm{ml}$. Cross reactivity with non-E prostaglandins $<0 \cdot 4 \% .^{10}$

\section{(b) Leukotriene measurement}

Solid phase sorbent extraction, using RNP 1904 mini columns (Amersham) facilitated purification of $\mathrm{LTC}_{4}$ from the culture medium. The quantity of $\mathrm{LTC}_{4}$ in the eluate was measured using a radioimmunoassay technique (Amersham). The competitive binding principle,

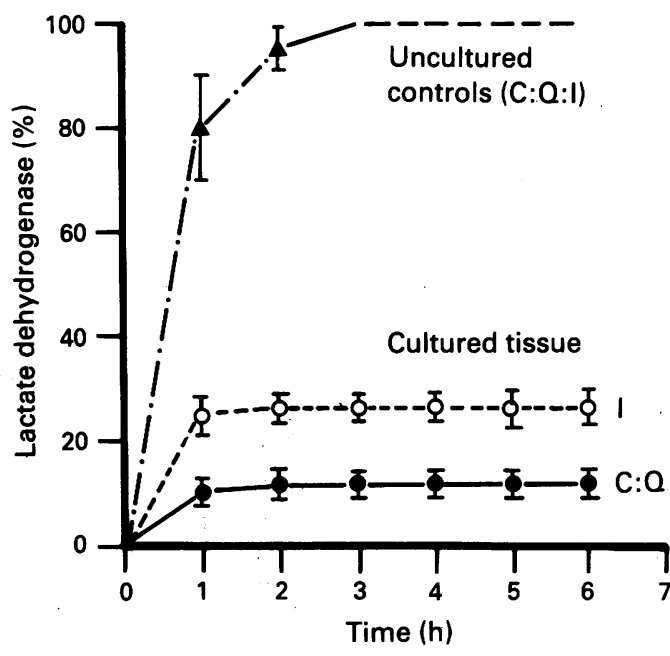

Figure 2: Lactate dehydrogenase release (\% hour) for a six hour culture period. $O$ and $\mathrm{O}=$ cultured tissues,

$\Delta=$ uncultured tissues. Tissue types: $C=$ control,

$\phi=$ quiescent; $I=$ inflamed. $n=20$ biopsies/tissue type for both cultured and uncultured tissues.

as stated above, was utilised but this time using tritium labelled $\mathrm{LTC}_{4}$. Separation of the antibody bound $\mathrm{LTC}_{4}$ was achieved by absorption of free $\mathrm{LTC}_{4}$ onto dextran coated charcoal. After centrifugation the quantity of radioactive ligand bound by the antibody was measured on a Beta counter. The $\mathrm{LTC}_{4}$ concentration was calculated from a standard curve. Performance characteristics of this assay were as follows: variation intra assay $17 \mathrm{pg} / \mathrm{ml}$; inter assay $29 \mathrm{pg} / \mathrm{ml}$; recovery $93 \%$; sensitivity $5 \mathrm{pg} / \mathrm{ml}$; cross reactivity with non sulphidopeptide leukotrienes $0.001 \% .^{11}$

The initial eicosanoid measurements, in pg eicosanoid per tube, were multiplied by the dilution factor, divided by the tissue weight and culture time. All eicosanoid results were expressed as pg mediator per mg wet tissue weight per hour.

\section{STATISTICAL ANALYSIS}

All values are expressed as the mean (1 SEM). Statistical comparisons for eicosanoid measurements were performed using unpaired $t$ tests. ${ }^{12}$ Graded inflammatory cell infiltrates were compared using $\chi^{2}$ tests and rank correlation. The inflammatory cell subpopulations/specific colon areas were analysed by analysis of variance (ANOVA). ${ }^{12}$ Two-tailed $\mathrm{p}$ values were used throughout.

\section{CHEMICALS}

Mini columns and the $\mathrm{LTC}_{4}$ RIA kit were purchased from Amersham, Lincoln Place, Aylesbury, Bucks, UK. The PGE $_{2}$ RIA kit was obtained from Du Pont (UK), Wedgewood Way, Stevenage, Herts, UK. The transport and culture medium was obtained from Life Technologies, 3 Washington Road, Paisley, Glasgow. Napp Laboratories provided the $X$ prep (Cambridge Science Park, Milton Rd, Cambridge, UK). DPX mounting compound and solvents were purchased from $\mathrm{BDH}$, Shaw Road, Speke, Liverpool, UK. The transport 
medium (L15), the culture medium (CMRL 1066) were obtained from Sigma Chemicals.

Results

\section{TISSUE VIABILITY}

\section{Lactate Dehydrogenase}

The release of lactate dehydrogenase is shown in Figure 2. The lactate dehydrogenase release from uncultured tissues was rapid and after three hours no enzyme activity was demonstrable in the tissue. This rapid release was similar in control, quiescent and inflamed tissues allowed to die at room temperature.

In comparison, the cultured tissues released less lactate dehydrogenase. There was no significant difference between control and quiescent biopsies. Although the inflamed mucosa initially produced more enzyme activity, the release rate (after one hour) for all three tissues was $<1 \%$ / hour.

\section{MICROSCOPY}

After this short culture period of four hours no histological changes were noted when compared with precultured tissue. Similarly there were no demonstrable structural changes at the electron microscopic level.

\section{COCULTURE}

\section{(a) PROCTOSIGMOIDITIS GROUP}

\section{(i) $P G E_{2}$ production}

The rate of $\mathrm{PGE}_{2}$ production (pg/mg wet tissue/ hour) for a series of cocultures is shown in Figure 3. The rate of $\mathrm{PGE}_{2}$ produced by two pieces of control tissue $(C+C$, column 1) was 184 (16). Coculture of two pieces of quiescent mucosa, removed from the ascending/transverse colon, yielded similar amounts of $\mathrm{PGE}_{2}(212(15))$ but two pieces of inflamed mucosa produced significantly more $\mathrm{PGE}_{2}(\mathrm{I}+\mathrm{I}=986$ (31) $\mathrm{p}<0.001)$. Coculture of one piece of inflamed and one of control mucosa (I+C) produced 534.8 (18) pg of $\mathrm{PGE}_{2} / \mathrm{mg}$ wet tissue hour. This corresponded well with the expected quantity of $\mathrm{PGE}_{2}$ calculated from mean production of $\mathrm{PGE}_{2}$ from $\mathrm{C}+\mathrm{C}$ and $\mathrm{I}+\mathrm{I}$, divided by the tissue weight $(\mathrm{I}+\mathrm{C}$ calculated $=555 \cdot 4)$. The expected quantity of $\mathrm{PGE}_{2}$ produced by an inflamed and quiescent combination was calculated in the same way (I+ $Q$ calculated $=574 \cdot 6)$. When this $I+Q$ coculture was performed, however, the mean value for $\mathrm{PGE}_{2}$ production was greater than expected (798 (77) $\mathrm{p}<0.01)$ although there was considerable variability in results. An examination of the results revealed two distinct subgroups. In the first $\left(I+Q_{1}\right)(n=$ eight patients) there was no significant difference between the expected $(574 \cdot 6)$ and observed $\cdot(561$ (24)) quantities of $\mathrm{PGE}_{2}$ produced. In the second $\left(\mathrm{I}+\mathrm{Q}_{\mathrm{II}}\right)(\mathrm{n}=12$ patients) significantly more $\mathrm{PGE}_{2}$ was produced (964 (20), p<0.01). Moreover there was no significant different between this latter inflamed/ quiescent coculture group $(964(20))$ and a

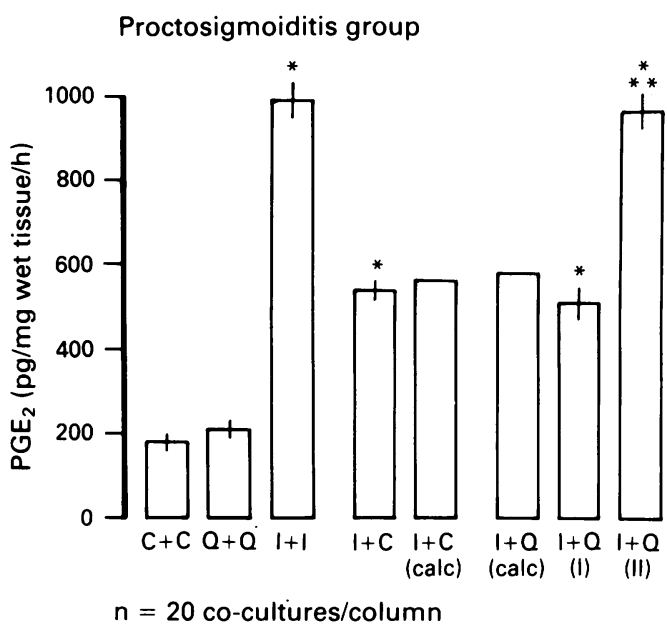

Figure 3: Prostaglandin $E_{2}$ production ( $p g / m g$ wet tissue/hour) by cocultured mucosal biopsies in patients with proctosigmoiditis (mean (SEM)). Mucosal type: $C=$ control; $Q=$ quiescent, $I=$ inflamed. Calc = calculated value (see text). $Q=$ quiescent,$I=$ inflamed. Calc $=$ calculated value $($ see text $)$
$(i)=I+Q$ co-culture, non-responding subgroup, $(i i)=I+Q$ co-culture, responding subgroup. ${ }^{\star}$ Significantly different from

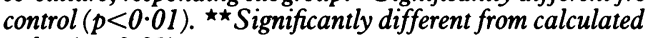
value $(p<0 \cdot 01)$.

combination of two inflamed biopsies (986 (31)). Of the eight patients with non-responding quiescent mucosa three were taking mesalazine, two were taking sulphasalazine and three were using topical steroids while in the 12 patients with responsive proximal mucosa seven were taking mesalazine, one sulphasalazine, and four topical steroids. In the first group ( $\mathrm{n}=$ eight) the proximal, macroscopic extent of inflammation was $15(2 \cdot 5) \mathrm{cm}$, compared with $26(8 \cdot 4) \mathrm{cm}$ for the second group $(p<0.05)$

Furthermore, there was no significant difference in $\mathrm{PGE}_{2}$ release when comparing either quiescent mucosal combinations from the non-responding group with the responding group $\left(\mathrm{Q}_{\mathrm{I}}+\mathrm{QI}_{1}=206(11) v \mathrm{Q}_{\mathrm{II}}+\mathrm{Q}_{\mathrm{II}}=220\right.$ (16): $\mathrm{NS}$ ) or cocultured inflamed tissue from the same groups $\left(\mathrm{I}_{\mathrm{I}}+\mathrm{I}_{\mathrm{I}}=997(24) v \mathrm{I}_{\mathrm{II}}+\mathrm{I}_{\mathrm{II}}=978(32)\right.$ : NS) (Table 1). Coculture of inflamed tissue from either group with quiescent mucosa from the responding group $\left(\mathrm{Q}_{\mathrm{II}}\right)$ however, resulted in a significant increase in $\mathrm{PGE}_{2}$ production when compared with the respective calculated value $\left(\mathrm{I}_{\mathrm{I}}+\mathrm{Q}_{\mathrm{II}}=929 \quad(26) \quad v \quad \mathrm{I}_{\mathrm{I}}+\mathrm{Q}_{\mathrm{II}} \quad(\mathrm{calc})=608\right.$; $\mathrm{I}_{\mathrm{II}}+\mathrm{Q}_{\mathrm{II}}=948 \quad(29) \quad v \quad \mathrm{I}_{\mathrm{II}}+\mathrm{Q}_{\mathrm{II}} \quad$ (calc) $=599$, $\mathrm{p}<0.001$ ) (Table I). The yield of $\mathrm{PGE}_{2}$ from coculture of inflamed tissue from either group with non-responding quiescent mucosa $\left(\mathrm{Q}_{\mathrm{I}}\right)$, was similar to the calculated value (Table I).

\section{(ii) Leukotriene production}

Coculture of two 'inflamed' tissues produced significantly more $\left.\mathrm{LTC}_{4}(\mathrm{I}+\mathrm{I}=590)(46)\right)$ than either two quiescent $(\mathrm{Q}+\mathrm{Q}=157(18))$ or two control biopsies $(\mathrm{C}+\mathrm{C}=112(11))(\mathrm{p}<0.001)$ (Fig 4). For the inflamed and control combination, the observed $(I+C=342(31))$ and expected (356) values were not significantly different. As with the $\mathrm{PGE}_{2}$ results, however, the inflamed and quiescent combination produced a wide range of values (mean $I+Q=445$ (62). Again two well defined groups were revealed; one $(n=$ eight) generated similar quantities of $\mathrm{LTC}_{4}$ to 
TABLE I Eicosanoid production by inflamed and quiescent tissue cocultures

\begin{tabular}{|c|c|c|}
\hline Coculture & $\begin{array}{l}P G E_{2} \\
p g / m g \text { wet weight/hour }\end{array}$ & $\begin{array}{l}\text { LTC } \\
\text { pg/mg wet weight/hour }\end{array}$ \\
\hline $\begin{array}{l}I_{(i)}+I_{(i)} \\
Q_{(i)}+Q_{(i)} \\
I_{(i)}+Q_{(i)} \\
I_{(i)}+Q_{(i)} \text { calc } \\
I_{(i i)}+Q_{(i)} \\
I_{(i i)}+Q_{(i)} \text { calc } \\
I_{(i i)}+I_{(i i)} \\
Q_{(i i)}+Q_{(i i)} \\
I_{(i i)}+Q_{(i i)} \\
I_{(i i)}+Q_{(i i)} \text { calc } \\
I_{(i)}+Q_{(i i)} \\
I_{(i)}+Q_{(i i)} \text { calc }\end{array}$ & $\begin{array}{l}997(24)^{\star} \\
206(11) \\
554(21)^{\star} \\
601 \\
537(14)^{\star} \\
592 \\
978(32)^{\star} \\
220(16) \\
948(29)^{\star} \dagger \\
599 \\
929(26)^{\star} \dagger \\
608\end{array}$ & $\begin{array}{l}604(32)^{\star} \\
151(14) \\
364(19)^{\star} \\
378 \\
379(16)^{\star} \\
369 \\
587(40)^{\star} \\
164(19) \\
566(31)^{\star} \dagger \\
375 \\
578(24)^{\star} \dagger \\
384\end{array}$ \\
\hline
\end{tabular}

$\mathrm{C}=$ control, $\mathrm{Q}=$ Quiescent, $\mathrm{I}=$ Inflamed, Calc $=$ calculated, (i) = non-responding subgroup $(\mathrm{n}=$ eight $),(\mathrm{ii})=$ responsive subgroup $(n=12), *$ significantly different from quiescen $(p<0.01), \dagger=$ significantly different from calculated value $(\mathrm{p}<0.001)$

the calculated value (actual $\mathrm{I}+\mathrm{Q}=352$ (18) $v$ calculated 368); the other $(n=12)$ produced not only significantly more $\mathrm{LTC}_{4}$ than the calculated value $(\mathrm{I}+\mathrm{Q}=586(35) v$ calculated $368 ; \mathrm{p}<0.01)$ but also similar quantities to a combination of two inflamed biopsies. These two groups consisted of the same patients subdivided on the basis of their $\mathrm{PGE}_{2}$ production rates. Furthermore, there was no significant difference in $\mathrm{LTC}_{4}$ release when comparing cocultures of either the two types of quiescent mucosa or the two types of inflamed mucosa (Table I). Coculture of inflamed tissue from either group with quiescent mucosa from the responding group $\left(\mathrm{Q}_{\mathrm{II}}\right)$ resulted in a significant increase in $\mathrm{LTC}_{4}$ production, when compared with the respective calculated value $\left(\mathrm{I}_{\mathrm{I}}+\mathrm{Q}_{\mathrm{II}}=578\right.$ (24) $v$ $\mathrm{I}_{\mathrm{I}}+\mathrm{O}_{\mathrm{II}}(\mathrm{calc})=384 ; \mathrm{I}_{\mathrm{II}}+\mathrm{Q}_{\mathrm{II}}=566(31) v \mathrm{I}_{\mathrm{II}}+\mathrm{Q}_{\mathrm{II}}$ (calc) $=375)$. Inflamed tissue from either group combined with non-responding quiescent mucosa $\left(\mathrm{Q}_{\mathrm{I}}\right)$ produced similar quantities of $\mathrm{LTC}_{4}$ to the respective calculated values (Table I).

\section{(iii) Histological studies}

In control tissue there was no significant difference between the mean counts for any cell type, in mucosal biopsies taken from the caecum, ascending, transverse, descending and sigmoid segments of the colon, and the rectum (Table II). Rectal and sigmoid biopsies from imflamed mucosa contained significantly more of each cell type determined (plasma cells, macrophages, lymphocytes, basophils, eosinophils, and poly-

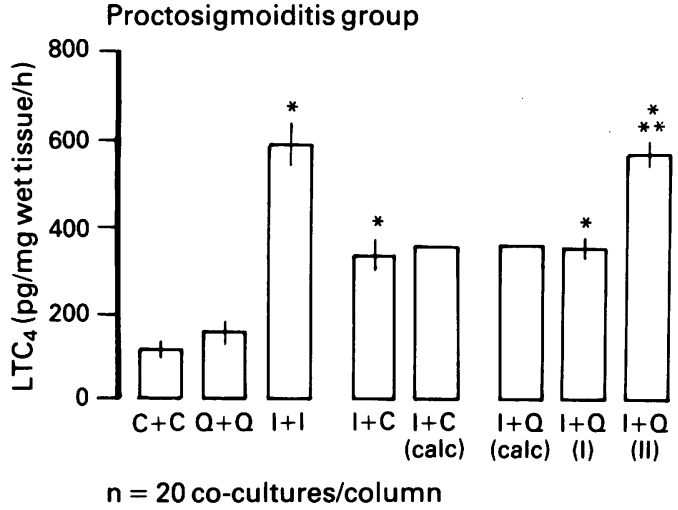

Figure 4 Leukotriene $C_{4}$ production ( $p g / m g$ wet tissue/hour) by cocultured mucosal biopsies in patients with

proctosigmoiditis (mean (SEM)). Mucosal type: $C=$ control; $Q=$ quiescent, $I=$ inflamed. Calc = calculated value (see text). (i) $=I+Q$ co-culture, non-responding subgroup, $(i i)=I+Q$ co-culture, responding subgroup. * Significantly different from control $(p<0.01) . \star \star$ Significantly different from calculated value $(p<0 \cdot 01)$.

morphonuclear cells) than control or quiescent mucosal biopsies, and the most marked increased was in the polymorphonuclear cells. Quiescent mucosa contained more macrophages and lymphocytes than control mucosa but only the increase in macrophage count was statistically siginificant $(\mathrm{p}<0 \cdot 02)$.

The histological grades correlated with the endoscopic grades.

When comparing the mean cell counts from the two groups of proctosigmoiditis, quiescent tissue from the group which exhibited the stimulated increase in eicosanoid output, contained significantly more macrophages $(p<0.04)$ and numerically more lymphocytes than the other subgroup.

There was a correlation only between the macrophage number and eicosanoid production $(\mathrm{p}<0.01)$ from quiescent tissue when the latter was co-cultured with inflamed tissue.

\section{(b) CROHN'S DISEASE GROUP}

\section{(i) $P G E_{2}$ production}

Compared with the control co-culture $(C+C=186 \cdot 4)$, the combination of two quiescent biopsies produced significantly more $\mathrm{PGE}_{2}$ $(\mathrm{Q}+\mathrm{Q}=296(31) \mathrm{p}<0.01)$ (Fig 5). Much greater amounts of $\mathrm{PGE}_{2}$ were generated by the inflamed combination $(\mathrm{I}+\mathrm{I}=1015(52), \mathrm{p}<0.005)$, how-

TABLE II Cell count per section mean (SEM); $\left.2000 \mu m^{2}\right)$ for each type of tissue

\begin{tabular}{|c|c|c|c|c|c|}
\hline Cell type & Control & $\begin{array}{l}\text { Quiescent } \\
\text { Proctosigmoiditis }\end{array}$ & Crohn's & $\begin{array}{l}\text { Inflamed } \\
\text { Proctosigmoiditis }\end{array}$ & Crohn's \\
\hline Neutrophil & $6 \cdot 24(0 \cdot 27)$ & \multirow{6}{*}{$\begin{array}{lc}\text { (i) } & 6.15(0.32) \\
\text { (ii) } & 6.94(0.29) \\
\text { (i) } & 19.19(0.3) \\
\text { (ii) } & 18.6(0.27) \\
\text { (i) } & 6.55(0.61) \\
\text { (ii) } & 10.45(0.74)^{\star} \\
\text { (i) } & 7.15(0.19) \\
\text { (ii) } & 8.02(0.21) \\
\text { (i) } & 8.6 \pm 0.19 \\
\text { (ii) } & 9.62 \pm 0.17 \\
\text { (i) } & 4.65 \pm 0.22 \\
\text { (ii) } & 4.51 \pm 0.19\end{array}$} & $7 \cdot 38(0 \cdot 37)$ & $123 \cdot 71+(1 \cdot 94)$ & $126 \cdot 12+(2 \cdot 1)$ \\
\hline Plasma cell & $18 \cdot 0(0 \cdot 37)$ & & $20 \cdot 52(0.35)$ & $31 \cdot 6+(0.44)$ & $32 \cdot 5+(0 \cdot 51)$ \\
\hline Macrophage & $6.06(0.57)$ & & $11.35(0.76) \dagger$ & $16 \cdot 25+(0.89)$ & $17 \cdot 43+(0.94)$ \\
\hline Lymphocyte & $6 \cdot 7(0 \cdot 16)$ & & $10 \cdot 36(0 \cdot 2) \dagger$ & $15 \cdot 9+(0 \cdot 16)$ & $16 \cdot 67+(0 \cdot 24)$ \\
\hline Eosinophil & $8 \cdot 32(0 \cdot 15)$ & & $8 \cdot 78(0 \cdot 27)$ & $21 \cdot 4+(0 \cdot 32)$ & $20.96+(0.34)$ \\
\hline Basophil & $4 \cdot 56(0 \cdot 17)$ & & $5 \cdot 51(0 \cdot 28)$ & $12 \cdot 96+(0 \cdot 54)$ & $12 \cdot 97 \dagger(0.66)$ \\
\hline
\end{tabular}

(i) $=$ non-responding subgroup $(n=$ eight $)$, (ii) $=$ responsive $\operatorname{subgroup}(n=12) ;{ }^{\star}=$ significant difference between $\left.i\right)$ and ii) $(p<0 \cdot 04)$, $\dagger=$ significantly different from control $(p<0 \cdot 01), n=10$ sections/tissue type. Number of fields per section counted was 10 . 


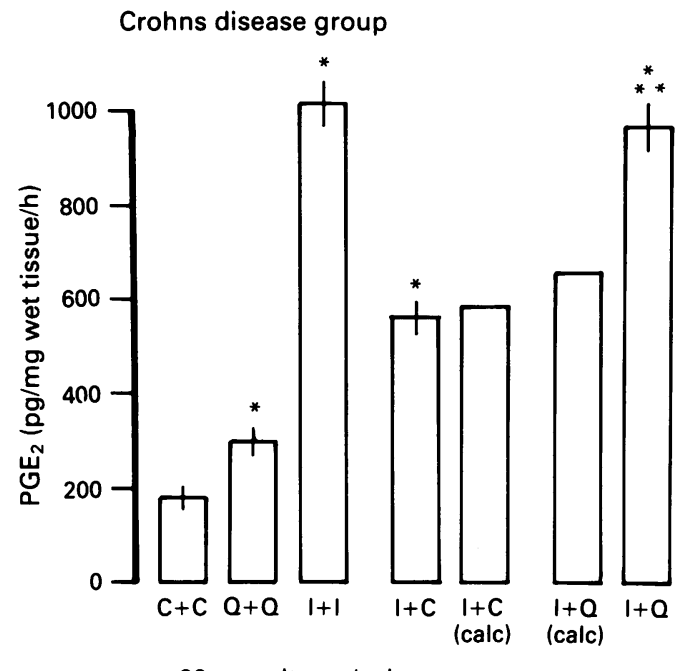

Figure 5 Prostaglandin $E_{2}$ production ( $p g / m g$ wet tissue/hour) by cocultured mucosal biopsies in patients with Crohn's colitis (mean (SEM)). Mucosal type: C=control, $Q=$ quiescent,$I=$ inflamed. Calc $=$ calculated value (see text). $\star$ Significantly different from control $(p<0 \cdot 01)$.

$\star \star$ Significantly different from calculated value $(p<0.01)$.

ever, the results for both the actual and calculated inflamed plus control coculture were 382 (29) and 396 respectively and these were not significantly different. The inflamed and quiescent coculture $(I+Q=964$ (49) produced significantly more $\mathrm{PGE}_{2}$ than the calculated value $(\mathrm{I}+\mathrm{Q}=665.8, \mathrm{p}<0.01)$ and similar amounts to the co-culture of two inflamed biopsies $(\mathrm{I}+\mathrm{I}=1015$ (15).

\section{(ii) Leukotriene production}

Coculture of two inflamed tissues yielded significantly more $\mathrm{LTC}_{4}$ than either two quiescent or two control tissues $(630$ (55) $v 223$ (24) and 113 (11) respectively, $p<0.01$ (Fig 6). The difference between the quiescent and control coculture $\mathrm{LTC}_{4}$ production rate was significant $(\mathrm{p}<0.01)$. The inflamed and quiescent coculture produced quantities of $\mathrm{LTC}_{4}$ similar to two

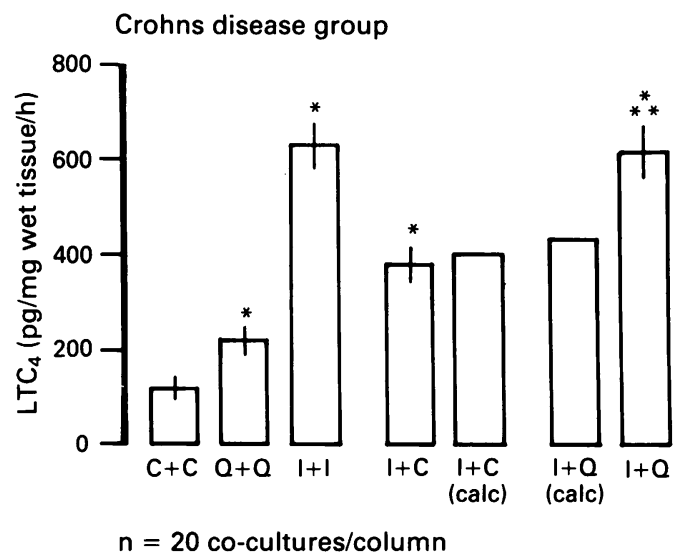

Figure 6 Leukotriene $C_{4}$ production (pg/mg wet tissue/hour) by cocultured mucosal biopsies in patients with Crohn's colitis (mean (SEM)). Mucosal type: $C=$ control; $Q=$ quiescent,

$I=$ inflamed. Calc = calculated value (see text)

$\star$ Significantly different from control $(p<0 \cdot 01)$

$\star \star$ Significantly different from calculated value $(p<0 \cdot 01)$. inflamed biopsies (616 (39) $v 630$ (55)) but significantly more than the expected value (407 $(\mathrm{p}<0.01)$.

\section{(iii) Histological studies}

The inflammatory cell grade of the inflamed biopsies was significantly higher than either quiescent or control mucosal grades $(p<0.001)$ The histological grade also correlated with the endoscopic grade $(r=0.79: p<0.005)$.

Irrespective of the colonic area, inflamed mucosa contained a significantly greater number of each variety of inflammatory cell when compared with the other two types of tissues $(p<0.01)$. Although the number of cells in quiescent mucosa was greater than in control mucosa this did not reach statistical significance for any cell type (Table II).

\section{COMPARISON BETWEEN PROCTOSIGMOIDITIS AND} CROHN'S DISEASE

The trends is eicosanoid production were similar for both groups, though the quiescent coculture in Crohn's patients produced significantly more $\mathrm{LTC}_{4}$ than the proctosigmoiditis group $(p<0 \cdot 01)$. Two subgroups were identified in the inflamed/quiescent proctosigmoiditis culture, on the basis of eicosanoid generation and macrophage number but a similar distribution was not seen in patients with Crohn's disease.

\section{Discussion}

A number of investigators have reported increased production of eicosanoids by colonic mucosa from patients with inflammatory bowel disease. ${ }^{2-413}$ Mucosal biopsies from patients with ulcerative colitis contained three, six, and 10 times the amounts of $\mathrm{PGE}_{2}, \mathrm{LTB}_{4}$, and 5HETE respectively, compared with normal biopsies. ${ }^{13}$ Cultured biopsies released increased amounts of $\mathrm{PGE}_{2}, \mathrm{PGF}_{2 \mathrm{a}}, 6 \mathrm{KetoPGF}_{1}, \mathrm{TXB}_{2}$, 12HETE, 15HETE, $\mathrm{LTB}_{4}$, and $\mathrm{LTC}_{4}$ into the culture medium compared with control biopsies. ${ }^{1-4}$ Similar results have been reported in experimental colitis in animals. ${ }^{14}$

Rectal dialysis techniques have also been used to show increased release of eicosanoids in vivo in both ulcerative colitis and Crohn's disease of the colon. ${ }^{4}$ is Somewhat less $\mathrm{PGE}_{2}, \mathrm{PGF}_{2}$ and $\mathrm{TXB}_{2}$ was released in Crohn's disease than in colitis and $\mathrm{LTB}_{4}$ release was raised in only a few patients with Crohns colitis. ${ }^{15} 16$

The present study describes a simple and reliable way of culturing colonic mucosal tissues either individually or combined, without interfering with the structural or functional integrity of the tissues. Moreover, the trends in lactate dehydrogenase release were not surprising. The initial rise exhibited by all tissues may be related to cell death secondary to the trauma of taking the biopsy and the length of time needed for oxygenated nutrient medium to bathe the cells. The difference between inflamed and the control/quiescent group over the first hour is probably because increased friability of inflamed tissue. These data confirm that inflamed mucosa from patients with proctosigmoiditis generates 
significantly more $\mathrm{PGE}_{2}$ and $\mathrm{LTC}_{4}$ than quiescent or control tissues and shows similar changes in Crohn's Disease.

The most interesting observation in the present study was the finding that coculture of inflamed and quiescent mucosal biopsy specimens produced greater amounts of prostaglandin and leukotriene than expected. In the proctosigmoiditis patients this was restricted to a subgroup of biopsies where production of mediators was markedly enhanced. In the other subgroup no such enhanced release was detected. In the former group it is difficult to escape the conclusion that quiescent proximal mucosa may be stimulated by soluble mediators released from inflamed tissue to liberate eicosanoids. Furthermore the degree of stimulation produced by inflamed mucosa from either patient subgroup was virtually identical. Thus is seems likely that this group of quiescent tissues are primed to respond in this way because non-responding quiescent mucosal biopsies cocultured with inflamed biopsies and also control mucosal biopsies treated in the same way produced only the expected quantities of these eicosanoids.

In seeking a cause for the difference between these two subgroups of quiescent mucosa it did not appear to reside in differences in treatment the patients were receiving. There was no segregation of patients receiving corticosteroids, 5ASA or sulphasalazine to one or other of the subgroups. The findings that the subgroup of patients, in which quiescent mucosa produced exaggerated amounts of eicosanoids, however, tended to have disease extending more proximally into the sigmoid colon, may be significant.

It is conceivable that this functionally abnormal, macroscopically normal, proximal mucosa in the patients with more extensive disease may indicate a propensity to develop more extensive colitis.

The source of the enhanced eicosanoid production in the inflamed/quiescent coculture is uncertain. It is likely to be lymphocytes, monocytes and/or macrophages in the quiescent biopsies. The number of macrophages present in the biopsies was significantly, if modestly, increased, and there was a slight non-significant increase in lymphocytes, but although this may account for the high production rates it also seems likely that eicosanoid release per cell is enhanced. This increased sensitivity may provide one mechanism by which proctosigmoiditis could spread proximally in those patients prone to develop total colitis.

Macrophages in their antigen presenting role may be upregulated after antigen exposure and thus may be 'primed' to trigger eicosanoid production more readily. We did not determine specific $\mathrm{T}$ cell lymphocyte subsets, however, and athough there was no significant difference in total lymphocyte counts between quiescent and control tissue, it is possible that an increase in a particular subset responsible for eicosanoid production was present but undetected.

The nature of the mediator released from inflamed mucosa which stimulated quiescent mucosa to produce eicosanoids was not investigated but bradykinin is a likely contender because it is known to cause release of arachidonic acid by receptor mediated phospholipase $\mathrm{A}_{2}$ activation in inflammatory cells. ${ }^{17-20}$ Other potential stimuli, however, including histamine, 5hydroxytryptamine, ${ }^{21}$ interleukin $1^{22} 23$ tumour necrosis factor and platelet derived growth factor, may also be involved. We are currently investigating these possibilities.

As in the proctitis group, inflamed tissue from Crohn's disease patients produced significantly more eicosanoid than either control or quiescent cocultures. Unlike the proctitis group, however, quiescent mucosa from Crohn's patients generated significantly more $\mathrm{PGE}_{2}$ and $\mathrm{LTC}_{4}$ than the control mucosa. It may be that quiescent mucosa between skip areas has a resident population of activated inflammatory cells. This high 'resting tone' of eicosanoid production by quiescent mucosa was significantly' greater than that generated by similar mucosa in the proctosigmoiditis group. This may again reflect increased number and/or priming of inflammatory cells, or the proximity to inflamed tissue. In addition to this significantly higher 'resting tone' in quiescent Crohn's mucosa, however, coculture with inflamed tissue produced a similar stimulation to that found in the responsive subgroup of proctosigmoiditis patients.

It should be pointed out that many of the patients from whom the biopsies were taken were being given corticosteroids or 5ASA preparations, each of which are known to be capable of inhibiting release of inflammatory mediators. It is conceivable therefore that our results are biased by this effect. We could not find a correlation between the measured eicosanoid release, however, and the medications taken in any group of patients. In any event such therapy would be expected to minimise inflammatory mediator release and would not account for the enhanced release we observed.

We conclude that apparently quiescent colonic mucosa in some patients with proctitis and all patient's with colonic Crohn's disease may be sensitised to release abnormal amounts of prostaglandins and leukotrienes and that it can be induced to do so by soluble mediators produced by actively inflamed tissue.

We are grateful to the Ileostomy Association for their financia support and interest in our research. We thank Carol McDonn for typing the manuscript.

I Sharon P, Ligumsky M, Rachmilewitz D, Zor U. Role of prostaglandins in ulcerative colitis. Enhanced production during active disease and inhibition by sulfasalazine. Gastroenterology 1978; 75: 638-40.

2 Ligumsky M, Karmeli F, Sharon P, Zor U, Cohen F, Rachmilewitz D. Enhanced thromboxane $\mathrm{A}_{2}$ and prostacyclin production by cultured rectal mucosa in ulcerative colitis and its inhibition by steroids and sulfasalazine. Gastroenterology 1981; 81: 444-9.

3 Sharon P, Stenson WF. Enhanced synthesis of leukotriene B by colonic mucosa in inflammatory bowel disease. Gastroby colonic mucosa in inflamr

4 Lauritsen K, Laursen, LS, Bukhave K, Rask-Madsen J. In vivo profiles of eicosanoids in ulcerative colitis, Crohn's colitis and clostridium difficile colitis. Gastroentrology 1988; colitis and $11-7$.

5 Rampton DS, Sladen GE. Relationship between rectal mucosal prostaglandin production and water and electrolyte transpor in ulcerative colitis. Digestion 1984; 30: 13-22.

6 Smith PL, Monizka DP, McCafferty GP, Wasserman MA Fondacaro JD. Effect of sulphidopeptide leukotrienes D and $\mathrm{E}_{4}$ on ileal transport in vitro in the rat and rabbit. $\mathrm{Am} f$ Physiol 1988; 255: G175-83.

7 Musch MW, Miller RJ, Field M, Siegl M. Stimulation of colonic secretion by lipoxygenase metabolites of arachidonic acid. Science 1982; 217: 1255-6.

8 Boughton-Smith NK, Hawkey CJ. Whittle BJR. Biosynthesis of lipoxygenase and cyclo-oxygenase products from ${ }^{1+} \mathrm{C}$ 
arachidonic acid by human colonic mucosa. Gut 1983; 24; 1176-82.

9 Riley SA, Mani V, Goodman MJ, Dutt S, Herd ME. Microscopic activity in ulcertive colitis: what does it mean? Gut 1990; 32;174-8.

10 Instruction manual for the measurement of prostaglandin $E_{2}$ in plasma and tissue samples. Stevenage: NEN Research (Du Pont de Nemours), 1988.

11 Leukotriene $C_{4} / D_{4} / E_{4}$ assay system. Aylesbury, Bucks: Amersham International plc, 1988.

12 Snedecor GW, Cochran WG. Statistical methods. 7th ed. Ames, Iowa, Iowa State University, 1980.

13 Peskar BM, Dreyling KW, Peskar BA, May B, Goebell H. Enhanced formation of sulfidopeptide leukotrienes in ulcerative colitis and Crohn's disease; inhibition by sulfasalazine and 5-aminiosalicylic acid. Agents Actions 1986; 18: 381-3.

14 Zipser RD, Nast CC, Lee M, Kao HW, Duke R. In vivo production of leukotriene $B_{4}$ and leukotriene $C_{4}$ in rabbit production of leukotriene $B_{4}$ and leukotriene $C_{4}$ in rabbit
colitis. Relationship to inflammation. Gastroenterology 1987; 92: 33-9.

15 Lauritsen K, Hansen J, Bytzer P, Bukhave K, Rask-Madden $\mathrm{J}$. Effects of sulphasalazine and disodium azodisalicylate on colonic $\mathrm{PGE}_{2}$ concentrations determined by equilibrium in vivo dialysis of faeces in patients with ulcerative colitis and health controls. Gut 1984; 25: 1271-8.

16 Lauritsen K, Laursen LS, Bukhave K, Rask-Madsen J. Effects of topical 5-aminosalicylic acid and prednisolone on prostaglandin $E_{2}$ and leukotriene $B_{4}$ levels determined by equilibrium in vivo dialysis of rectum in relapsing ulcerative colitis. brium in vivo dialysis of rectum in

17 Musch MW, Kachur JF, Miller RJ, Field M. Bradykinin and stimulated electrolyte secretion in rabbit and guinea pig intestine. F Clin Invest 1983; 71: 1073-83.

18 Cuthbert AW, Halushka PV, Margolius HS, Spayne JA. Mediators of the secretory response to kinins. $B r \mathcal{F}$ Pharm 1984; 82: 597-607.

19 Warhurst G, Higgs NB, Lees M, Tonge A, Turnberg LA. Site and mechanisms of action of kinins in rat ileal mucosa. $A m \mathcal{F}$ Physiol, 1987; 252: G293-300.

20 Lawson LD, Powell DW. Bradykinin stimulated eicosanoid synthesis and secretion by rabbit ileal components. Am $\mathcal{F}$ Physiol, 1987; 252: G783-90.

21 Munck LK, Mertz Nielsen A, Westh H, Bukhave K, Beubler $\mathrm{E}$, Rask-Madsen $\mathrm{J}$. Postaglandin $\mathrm{E}_{2}$ is a mediator of 5hydroxytryptamine water and electrolyte secretion in the hydroxytryptamine water and electroly

22 Kohan DE. Interleukin 1 regulation of prostaglandin $E_{2}$ synthesis by the papillary collecting duct. $f$ Lab Clin Med 1988 114: 717-23.

23 Cominelli F, Mast CC, Dinarello GA, Gentilini P, Zipser RD. Regulation of eicosanoid production in rabbit colon by interleukin 1. Gastroenterology 1989 97:1400.5, 